\title{
Investigation on pile-soil-tunnel interaction due to adjacent loaded pile row by 3D FEM
}

\author{
Narunat Heama ${ }^{1}$, Pornkasem Jongpradist ${ }^{2}$, Prateep Lueprasert ${ }^{1}$, and Suchatvee Suwansawat ${ }^{1}$ \\ ${ }^{1}$ Faculty of Engineering, King Mongkut's Institute of Technology Ladkrabang, Bangkok, Thailand \\ ${ }^{2}$ Faculty of Engineering, King Mongkut's University of Technology Thonburi, Bangkok, Thailand
}

\begin{abstract}
The effect of adjacent loaded pile row on the existing tunnel is analysed by 3D finite element method. The MRTA project is used as reference case in this study. The case study is divided into two cases, tunnel and pile tip located in soft clay and stiff clay, respectively. The pile diameter of $1 \mathrm{~m}$ and pile tip located at the elevation of tunnel crown with various number of piles within the row were considered. The analysis results are shown in terms of total soil displacement (without tunnel) and maximum tunnel deformations. Both total soil displacements and tunnel deformation increase with the number of piles and approach a maximum value when the number of piles is greater than 13 and 11 for cases tunnel in soft and stiff clay, respectively. This reveals that the tunnel deformation mechanism is primarily due to the soil displacement.
\end{abstract}

\section{Introduction}

The tunnel construction increases in the urban development to deal with the traffic congestion problems and resource supply. Typically, the tunnels are constructed underground along the major roads to avoid the building. In recent years, however, new buildings and infrastructures have been substantially constructed in the close proximity. Then, the existing tunnel is inevitably affected by the adjacent piles under loading as shown in Fig.1. An evaluation of the effect of loaded pile on the stability and integrity of tunnel is essential.

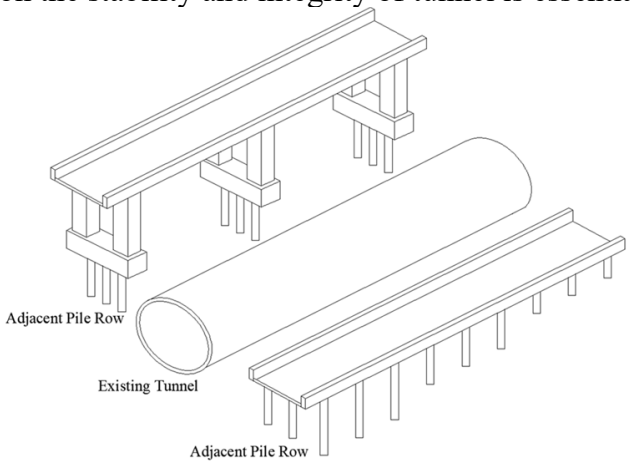

Fig. 1. New construction adjacent to existing tunnel in urban environment

Several researches have studied the mechanisms of soil-tunnel-pile interactions. Examples are the effect of nearby loaded bore pile on existing tunnel in London [12], the effect of multi-storey commercial building on two existing tunnels of Toronto subway in Canada [3]. In addition, the effect on existing tunnel due to adjacent bore pile under loading was analyzed by 3D finite element method (FEM) in Bangkok, Thailand [4-6]. Many researches focused on the effect on existing tunnel due to adjacent single pile under loading to study the response of tunnel. Only a few researches considered the effect of pile rows under loading on the existing tunnel. In previous research, the pile row and tunnel problem was analyzed assuming a 2D plane strain condition. Analysis under 2D plane strain condition using transformation technique for pile and 3D slice (using symmetry plane) were studied to evaluate and compare the effect of loaded pile row [7]. However, both conditions considered the ideal condition of which the number of pies in the row is great enough so that the plane strain condition can be considered at centre plane of the model. The results on that plane are thus in the conservative manner if the number of piles in the row is not that many. In engineering practice, the pile row condition is often encountered for bridge structures of which the number of piles in the row depend on the width. It is thus worth to know the minimum number of piles in the group that provides 2D plane strain condition at the centre plane. Besides, the 2D FEM cannot calculate the behaviour of soil between columns. Therefore, a 3D FEM analysis is required to analyse the effect of adjacent loaded pile rows on existing tunnel. Thus, this research focused on the number of piles within pile row in term of fully effect on existing tunnel by 3D FEM program. The data of MRTA was used in this research. The results are discussed in terms of total soil displacement and tunnel deformations.

\footnotetext{
* Corresponding author: narunat2835@gmail.com
} 


\section{Methodology}

\subsection{Geometrical parameters and a case study}

The geometrical parameters considered in this study are shown in Fig2(a). The tunnel diameter $\left(\mathrm{D}_{\mathrm{T}}\right)$ of $6.3 \mathrm{~m}$ with, the lining thickness of $0.3 \mathrm{~m}$, are considered with the constant depth $\left(\mathrm{L}_{\mathrm{T}}\right)$ of $20.0 \mathrm{~m}$ below the ground surface. The bored pile dimeter $\left(\mathrm{D}_{\mathrm{P}}\right)$ of $1.0 \mathrm{~m}$ with the length of $-13.7 \mathrm{~m}$ is defined. The pile spacing $(\mathrm{S})$ of $3 \mathrm{D}_{\mathrm{P}}$ and the clearance $(\mathrm{C})$ of $0.5 \mathrm{~m}$, which is the distance between the edge of bored pile to the edge of tunnel, were considered.

In this study, there are two case studies subsoil conditions. For the first case (Case 1), the tunnel and pile tip are located in soft clay. The second case (Case 2), the tunnel and pile tip are located in stiff clay. The number of piles within row is varied. The subsoil conditions and a piezometric drawdown of typical water pressure profile in Bangkok [8] are depicted in Fig 2(b).

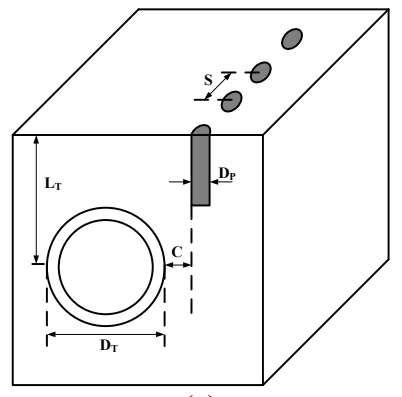

(a)

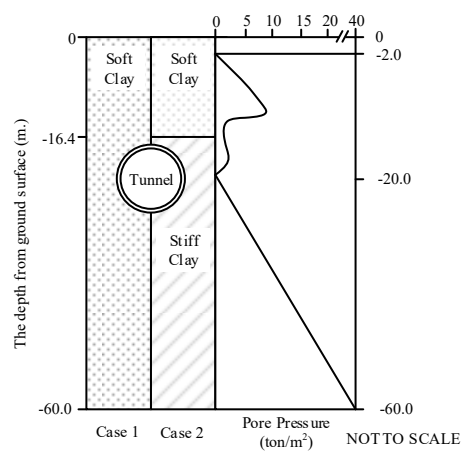

(b)

Fig. 2. Geometric parameters [4].

\subsection{Numerical model and FEA}

The static analysis of pile under loading was carried out by the FEM with implicit integration algorithm using PLAXIS 3D code. The mesh is shown in Fig 3. The 10node tetrahedral elements or the volume elements. were used to model the soil and hardening grouting layers with a suitable aspect ratio. The tunnel lining and EPBs were discretized into the 6-node triangular plate elements. The bored pile was modelled by the embedded elements. The dimension of model is $50 \mathrm{~m}(\approx 8 \mathrm{DT})$ in the transverse direction and $60 \mathrm{~m}(\approx 9.5 \mathrm{DT})$ in the vertical direction. In the longitudinal direction is $54 \mathrm{~m}(\approx 8.5 \mathrm{DT})$ ahead and behind the monitoring plane [10]. The simulation processes were divided into two steps. The first step, the tunnelling with shield method was simulated by following [9]. The second step, the impact of pile row on the tunnel deformation was simulated. The pile construction is not considered. The working load on plie rows is calculated by the $\alpha$ - method $(\mathrm{P}=416.54 \mathrm{kN})[11]$.

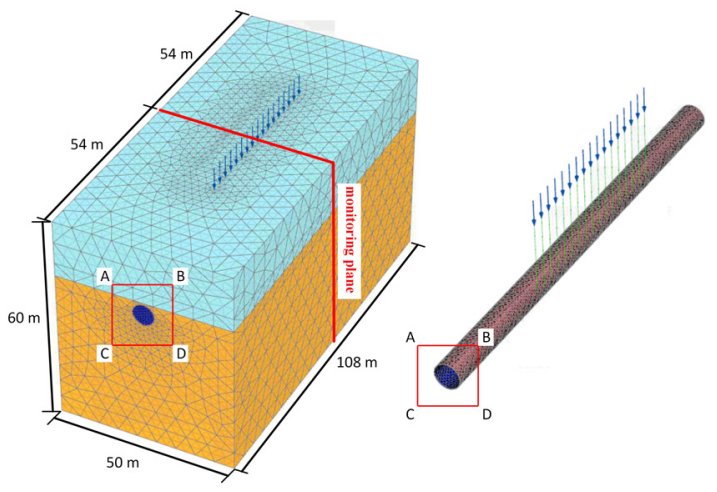

Fig. 3. Model diamantions and meshes.

\subsection{Boundary Condition and Initial Conditions}

\subsubsection{Boundary conditions}

Regarding the boundary conditions of numerical model, the movement at the sides of mesh was allowed in only vetical direction. At the bottom of mesh was fixed in all directions.

\subsubsection{Initial conditions}

The initial stress state is applied through the unit weight of soil layers and the coefficient of earth pressure at rest, $K_{0}$.

\subsection{Material properties}

Table 1. Soil model parameters [14]

\begin{tabular}{|c|c|c|}
\hline Soil layer & Soft clay & Stiff clay \\
\hline Material model & HS & HS \\
\hline$E_{\text {oed }}^{r e f}(\mathrm{kPa})$ & 5,000 & 60,000 \\
\hline$E_{50}^{r e f}(\mathrm{kPa})$ & 5,000 & 60,000 \\
\hline$E_{u r}^{r e f}(\mathrm{kPa})$ & 15,000 & 180,000 \\
\hline$\gamma_{\text {sat }}\left(\mathrm{kN} / \mathrm{m}^{3}\right)$ & 16 & 18 \\
\hline$v^{\prime} \quad(-)$ & 0.33 & 0.33 \\
\hline$\phi^{\prime} \quad\left({ }^{\circ}\right)$ & 22 & 22 \\
\hline$c \quad(\mathrm{kPa})$ & 5 & 18 \\
\hline$m \quad(-)$ & 1 & 1 \\
\hline$p_{\text {ref }}(\mathrm{kPa})$ & 100 & 95 \\
\hline
\end{tabular}


Table 1 depicts the soil parameters. Tunnel lining, pile and grouting layer uses the linear elastic model. The soft and stiff clay are assigned by hardening soil model (HS) [12]. The properties of soils and material parameters for the simulations in Bangkok subsoil are calibrated by [1314] and has been used in previous research [15].

\subsection{Measurement}

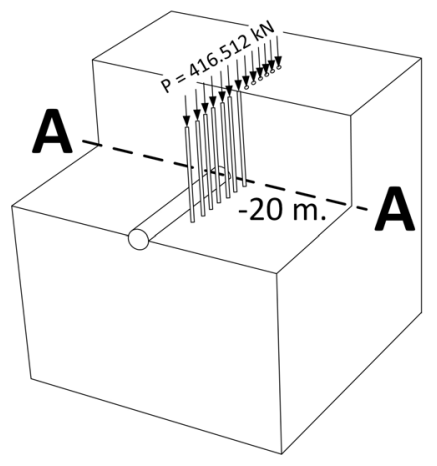

Fig.4. Monitoring section A-A.

The influence of number piles is evaluated in terms of the total displacement of soil at the tunnel axis (without tunnel) referred from Schroeder et al., 2004 [1] as shown in Fig.4. From study of Luepraset et al., (2017) [6], the shape of tunnel deformation is ellipse and nonsymmetric nature when affected by adjacent loaded pile located in single side. The proposed method of Luepraset et al., (2017), which can appropriately capture the ellipse and non-symmetric shapes in terms of the maximum tunnel deformations, are used to assess the influence of number piles in this study.

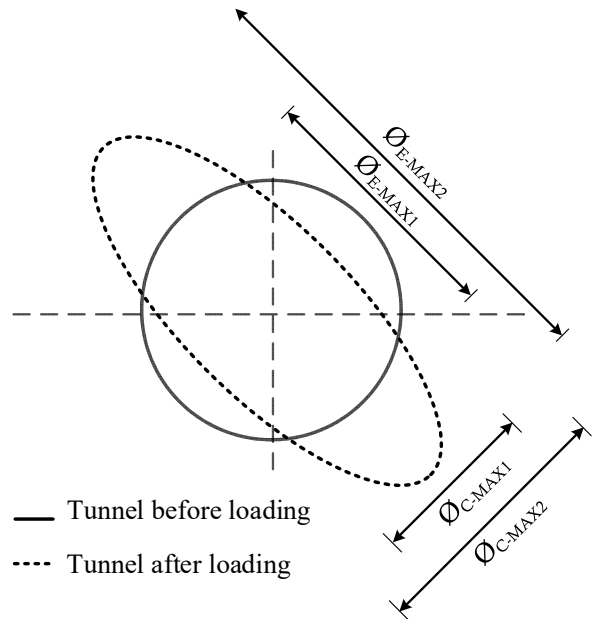

Fig. 5. The maximum changes of tunnel diameter

Figure 5 depicts the calculating method of maximum tunnel deformations. The calculation of the maximum changes of tunnel diameters are shown in Eq. (1) and (2). When $\phi_{1}$ and $\phi_{2}$ are tunnel diameters before and after the effect of pile rows under loading, respectively.
$\Delta \phi_{E}=$ maximum extension change of tunnel dimeter

$$
\Delta \phi_{E}=\phi_{E 2}-\phi_{E 1}
$$

$\Delta \phi_{C}=$ maximum contraction change of tunnel dimeter

$$
\Delta \phi_{C}=\phi_{C 2}-\phi_{C 1}
$$

\section{Analysis Results}

The total soil displacement and the change in tunnel diameter in terms of both maximum extension and maximum contraction deformations due to adjacent pile rows under loading are presented in this section.

\subsection{Total displacement of soil at depth of $20 \mathrm{~m}$.}

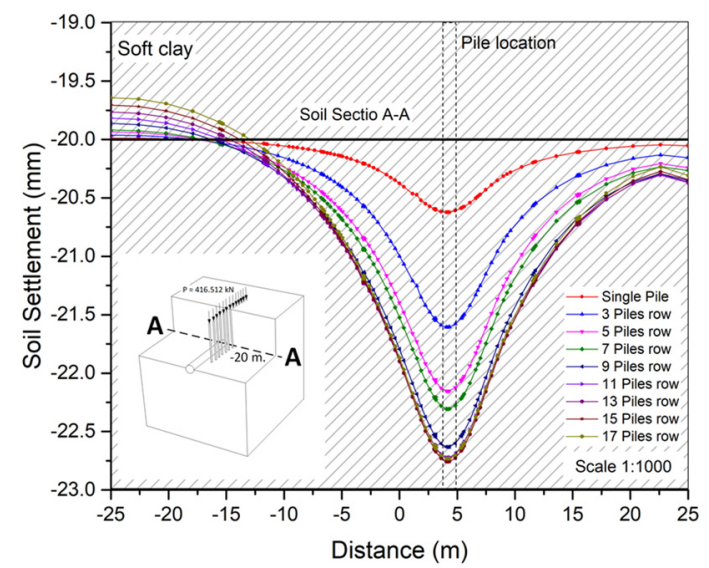

Fig. 6. soil displacement in case 1.

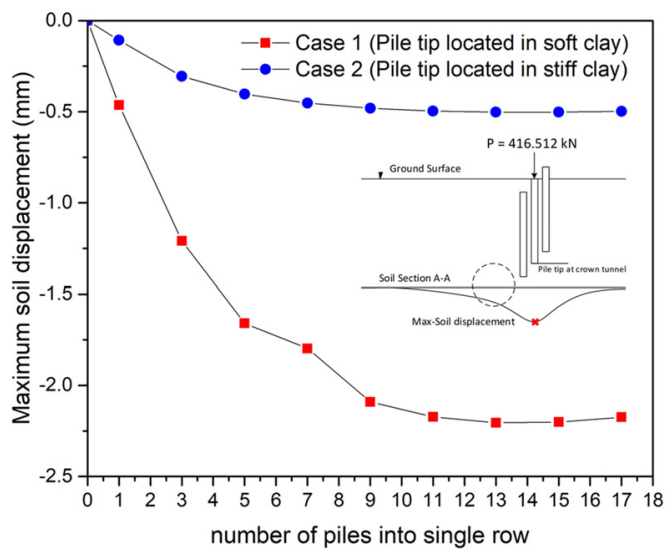

Fig. 7. the maximum soil displacement at depth of $-20 \mathrm{~m}$.

Figure 6 shows the total displacement profile of soil at the A-A section (without tunnel) for the case where pile tip is located in soft clay (Case 1). The total soil displacement increases with increasing number of piles. The maximum values with different pile numbers occur when the number of bored pile reaches 11. The maximum total soil displacement with number of piles within row are depicted in Fig.7. A similar tendency of 
both cases can be seen, but the magnitude of total soil displacement for Case 2 is smaller. The maximum total soil displacements are constant when the number of pile within row reaches 13 and 11 for case 1 and case 2 respectively.

As mentioned above, the soil displacements when the tunnel is located in soft clay (case 1) are larger than those in stiff clay (case 2). The movements of soil are principally due to pile load, load transfer behaviour from the pile and stiffness of the soil layer.

\subsection{Tunnel deformation}

The maximum extension change $\left(\Delta \phi_{\mathrm{E}}\right)$ and the maximum contraction change $\left(\Delta \phi_{C}\right)$ in tunnel diameter due to the influence of the number piles in the row are shown in this section. $\Delta \phi_{E}$ and $\Delta \phi_{C}$ gradually increase with increasing pile number. However, when the 11 piles and 9 piles for tunnel located in soft and stiff clay respectively is modelled, $\Delta \phi_{E}$ and $\Delta \phi_{C}$ becomes maximum and constant even larger number of piles is modeled. Since, load transfer from the pile to surrounding soil of the tunnel induces the tunnel deformation and the tunnel lining is stiffer than the soil.

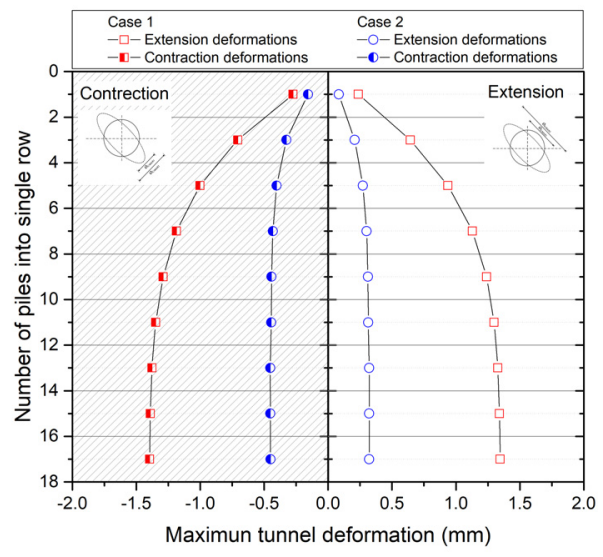

Fig. 8. the change of the tunnel diameters.

\section{Conclusion}

In this research, the effect of the number of piles in the row for piles under loading on the existing tunnel are investigated by $3 \mathrm{D}$ finite element method. The total soil displacements and the maximum change of tunnel diameters were observed. The conclusion of this study are as follows:

1. The total soil displacements are fully mobilized when number of piles within row reaches 13 and 11 for case 1 and case 2, respectively.

2. The maximum tunnel deformation in terms of both extension and contraction deformations are constant when the number of piles in row are 11 piles or Case 1 and 9 for case 2 .
3. Both soil movement and tunnel deformation in case 2 are smaller than those of case linspite that the applied load of case 2 is higher. This implies that the tunnel deformation is primarily due to the surrounding soil movement.

\section{Acknowledgment}

The authors wish to express their gratitude to Thailand Research Fund (TRF) and 1D2 Group Co. Ltd. for the financial support through Grant PHD60I0032 and the Ladkrabang Underground and Tunneling Innovation Center (LUTIC) under Grant KREF035001.

\section{References}

1. F.C. Schroeder, D.M. Potts and T.I. addenbrooke, Geotechnique, 54, 351-362 (2004)

2. L.J. Benton and A. Fhillips, in: Proc. $10^{\text {th }}$ Eur. Conf. Soil Mech. Fdn Engng. Florence, 2, 665-668 (1991)

3. Abdel M-Meguid, R.K. Rowe and K.Y. KY, Geomechanics, 2, 447-469 (2002)

4. N. Heama, P. Jongpradist, P. Lueprasert and S. Suwansawat, Int. J. Geomate, 12, 63-70 (2017)

5. P. Lueprasert, P. Jongpradist, K. Charoenpak, P. Chaipanna and S. Suwansawat, Maejo Int. J. sci. technol., 9, 209-223 (2015)

6. P. Lueprasert, P. Jongpradist and P. Jongpradist, Tunn. Under. Space Technol., 70, 166-181 (2017)

7. J.C. Chai, S. Shrestha, T. Hino, W.Q. Ding, Y. Kamo, J. Carter, Comput. Geotech., 68, 28-37 (2015)

8. S. Suwansawat, Ph.D. Thesis of Massachusetts Institute of Technology, (2002)

9. P. Lueprasert, P. Jongpradist and S. Suwansawat, Int. J. Geomate, 12, 51-57 (2017)

10. E.O. Mroueh and I. Shahrour Int. J. Numer. Anal. Methods Geomech, 26, 217-230.

11. A.W. Skempton, Geotechnique, 2, 153-173 (1959)

12. T. Schanz, P.A. Vermeer and P.G. Bonnier, In: Beyond 2000 Comput. Geotech. 10 Years PLAXIS Int. Proc. Int. Symp. Beyond 2000 Comput. Geotech. Amsterdum Netherlands 1820 March, 281296 (1999)

13. R.E. Prust, J. Davies and S. Hu, Transport. Res. Rec. J. Transp. Res. Board, 207-217 (2005)

14. T. Rukdeechuai, P. Jongpradist, A. Wonglert and T. Kaewsri, EIT Res. Dev. J., 20, 17-28 (2009)

15. P. Jongpradist, T. Kaewsri, A. Sawatparnich, A. Suwansawat, S. Youwat, W. kongkitkul and J. Sunitsakul, Tunn. Under. Space Technol., 34, 96109 (2013) 